ounces of lard. The wound was dressed with this ointment every morning for seven days. The application gave rise to but little local mischief, except that the temperature was slightly raised, and that a slight oozing of matter took place from a point removed a slight distance from the wound. From the time of the first dressing, the animal lost appetite, but throughout was neither purged nor vomited. He refused food, became gradually thin and exhausted, and died as from inanition, without any other remarkable symptoms.

The dog was sent to me directly after death: I examined him seventy-two hours after the fatal result. The cadaveric rigidity was well marked. In this as in the preceding cases, intense congestion of the internal organs was the most striking general appearance of a pathological kind. The blood was fluid, and such few clots as were met with were loose and dark in colour. The heart was filled with blood on both sides: the aorta was full of blood. The lungs were inflated, of a pink colour, and much less free from congestion than the other organs. There was no indication whatever of pulmonary inflammation. The bronchial membrane was healthy. The liver was congested; the spleen natural. The stomach contained ten drachms of a very dark, thick, bloody-looking mucus. The inner surface of the stomach had the same red appearance seen in the before-named cases, mapped out much in the same manner, and situated in the same locality. There was no ulceration. The intestines held no solid matter, but were thinly coated with a bloody mucus, like that in the stomach. The whole of the intestinal canal was injected, and the colon and rectum presented bloody spots as from a rupture of the minute vessels, but there was no actual nlcerated spot. The kidneys were of a purple colour, from congestion. The bladder was full of urine.

The results of the analysis in this case were as follows:The brain contained no trace of the poison. The lungs gave marked evidence of its presence. The heart gave very abundant proof of the presence of the poison. The blood yielded only traces (seven drachms was the amount acted on). The contents of the stomach (ten drachms) yielded abundant evidence. The stomach itself, after being washed, yielded distinct evidence. The liver and spleen yielded a much greater amount than any other structure. The kidneys yielded dis. tinct evidence. The urine gave distinct evidence. The rectum gave abundant evidence. The contents of the intestines gave distinct evidence. The intestines themselves gave distinct evidence. The soft parts of the back of the neck, at the point where the antimonial was applied during life, yielded the barest trace of antimony.

In this experiment we see that antimony, received slowly into the system, may cause death-may be present in almost every organ, and yet may not excite, during the lifetime of the animal, any of the symptoms of vomiting, purging, and spasms, which are usually set down as the specific signs of antimonial poisoning.

The liver, in this instance, was again the chief depôt of the poison.

Hinde-street, Manchester-square, May, 1856.

ON THE

\section{ADMINISTRATION OF ERGOT OF RYE.}

\section{By WILLIAM ROSE, Esq., F.R.C.S.}

ON January 28 th last I was called in by a practitioner in a ueighbouring town to a woman in labour with twins, one of which had been born thirty-six hours before. From that time there had been a total absence of uterine pain. She was at her full time, in good health, and had borne several children before. There was no urgent symptom whatever.

On examination, I found the os uteri and soft parts in a perfectly lax state. The child was alive; the head presented, but had made no descent from its situation in utero; there was ample capacity of the pelvis, and no impediment to its birth, as far as could be ascertained, beyond simple want of uterine action to expel it. The question appeared to be, whether to turn the child at once after so considerable a lapse of time, or first to try the effect of ergot, the conditions being so favourable to its action. The latter was determined upon, and half a drachm of the fresh powder given in tepid water. At the expiration of a quarter of an hour, active expulsive action of the uterus was produced, and, after three pains, the child was born in a vigorous, healtiny state. The after progress of the case was completely satisfactory.

High Wycombe, Bucks, April, 1856.

\section{ON THE DETECTION OF STRYCHNINE.}

Bx F. CRACE CALVERT, Esq., F.C.S.,

PROFGSSOR OF CHEMISTRY TO THE ROYAX INSTITUTION, MANCHESTEI, AND TATE LECTURER AT THE ROYAL MEDICAL SCHOOX; MANCHESTER,

HaVing noticed a great deal of discussion in various newspapers as to the length of time after death in which strychnine can be discovered in the stomach, I am induced to publish the following fact, which will prove that strychnine will resist decomposition in the stomach for the space of nearly one month after death.

In 1849, several dogs of the Cheshire pack of hounds were wilfully poisoned, and one of them was brought to my laboratory for examination. From the description which was given to me of the peculiar symptoms which accompanied the rapid death of these dogs, and also from the fact that I could observe no peculiar pathological appearance in the stomach and intestines, I was led to believe that they had died from the effects of strychnine. I therefore treated the contents of the stomach as follows:- It was put to digest for twenty-four hours, with pure alcohol of specific gravity 0.840 , slightly acidulated with pure hydrochloric acid. The whole was then thrown on a filter, and the filtrate concentrated and neutralized. The precipitate which was thus produced was dried and exhausted with alcoho of specific gravity $0 \cdot 840$. This alcoholic solution was evaporated to dryness in a water bath, and the residue treated with very dilute hydrochloric acid. This was again neutralized, and the deposit which fell re-dissolved in dilute hydrochloric acid. This solution was then evaporated to dryness, and the residue treated with the various tests characterizing strychnine, when its presence was clearly indicated.

As the master of the hounds attached great importance to the case, he requested me to obtain a sufficient amount of poison from the stomachs of some of the other dead dogs, that I might not only be convinced of the presence of the poison, but might also bring some of the extracted strychnine into court. To enable me to do so several dogs were disinterred and forwarded to my laboratory, and the space of time which had elapsed from the date of death to the time when I submitted them to analysis was at least three weeks, and still I perfectly succeeded in extracting strychnine from the stomach of the dogs, and exhibiting it in the state of crystallized hydrochlorate.

Amongst other persons who witnessed this fact was J. A. Ransome, Esq., Surgeon to the Royal Infirmary, Manchester. Manchester, May, 1856.

\section{distititor}

OF THE PRACTICE OF

\section{MEDICINE AND SURGERY IN THE}

\section{HOSPITALS OF LONDON.}

Nulla est alia pro certo noscendi via, nisi quam plurimas et morborum et dissectionum historias, tam aliorum proprias, collectas habere et inter se comparare.-Norgagis. De Sed. et Caus. Norb. lib. 14. Proœmium.

\section{UNIVERSITY COLLEGE HOSPITAL.}

EXTRAVASATION OF BLOOD INTO THE CALF OF THE LEG; HEMORRHAGIC DIATHESIS; OPENING OF A CAVITY FILIED WITH COAGULA, EXTENDING FROM THE POPLITEAL SPACE ABOVE THE IKNEE DOWN TO THE FEEL; ACTUAL CAUTERX TO ARREST THE BLERDING, AND TOURNIQUET TO THE FEMORAL ARTERY; EXTENSION OF THE CAVITY UP THE THIGH, WITH GDEMA AND COMMENCING GANGRENE; AMPUTATLON OF THE THIGH; FATAL TERMINATION; DISSECTION OF THE LIMB.

\section{(Under the care of Mr. ERICHsEn.)}

THERE is a condition which now and then presents itself to the notice of the surgeon,-though fortunately a rare one,known as the hæmorrhagic diathesis, from the great tendency, we may say, to uncontrollable bleeding from the slightest and most trivial wounds and bruises, ending not unfrequently in death, especially in children. This peculiar diathesis has been 